\title{
Genetically Modified Birds
}

\author{
Chidinma Adanna Levi ${ }^{1}$, Daniel Don Nwibo ${ }^{2}$, Christian Onyeka Chukwuka ${ }^{3}$, \\ and Chidimma Linda Mbadugha ${ }^{4}$ \\ ${ }^{1,3}$ Department of Zoology and Environmental Biology, Faculty of Biological Sciences, University of Nigeria, \\ Nsukka, Enugu State, Nigeria. \\ ${ }^{2}$ Laboratory of Pharmaceutical Microbial Chemistry, Graduate School of Pharmaceutical Sciences, University \\ of Tokyo, Japan \\ ${ }^{4}$ Pharmaceutical Microbiology Unit, Department of Microbiology, University of Nottingham, United Kingdom.
}

\begin{abstract}
Genetic engineering, which is synonymous to genetic modification, is the designed alteration of the genetic make-up of an organism and it is the basis for modern biotechnology. on the other hand, biotechnology is the application of science in production of goods and services using biological agents. The cell which is the functional unit of life contains two kinds of nucleic acids: Deoxyribonucleic acid (DNA) and the Ribonucleic acid (RNA). While the DNA is the genetic material, the RNA functions in protein synthesis. The tools and method for genetic modification include; gene insertion, gene deletion and gene regulation. Vectors are the biological vehicles used to transport DNA into host cells and without them, the whole process will be almost impossible. Birds belong to the class of aves and are characterised by presence of feathers. They are classified into precocious, semi precocious altricial and semi altricial based on development. However, birds can be modified for improved egg production, meat production, erythropeitin production and bird flu resistance. That notwithstanding, concerns have been raised on its effect on the environment and human health risks including concerns for modern birds and their own health. Whatever the case may be, the choice to consume transgenic birds should be left to the consumers, therefore, clear distinctions should be made between transgenic and nontransgenic bird for consumers to choose.
\end{abstract}

Keywords: Genetics, modified birds

\subsection{Definition Of Terms}

\section{Genetic Engineering}

Genetic modification, genetic engineering, genetic manipulation and recombinant DNA techniques are all essentially synonymous terms used as shorthand to describe the process by which genes can be transferred by researchers from one organism to another [1].

(a). Genetic Engineering: Genetic engineering is synonymous to genetic modification. This simply means the designed alteration of the genetic make-up of an organism. It is the basis for modern biotechnology. Mutation and crossbreeding is not genetic engineering because, engineering is all about designing, production and construction. Genetic engineering makes use of the fact that the DNA is the unit controlling expression of traits and features since the DNA codes for the RNA's which in turn codes for protejns

(b). Biotechnology: it is the application of science in production of goods and services using biological agents. Biotechnology is a collective term for a group of technologies that use biological matter or processes to generate new and useful products and processes and that as such, it ranges in complexity and maturity from ancient brewing and bread-making techniques to genetic modification through hybridization and interbreeding of plants and animals, as well as the manipulation of individual genes in humans, animals, plants and micro-organisms [2].

\subsection{Dna; Its Structure And Function}

The cell which is the functional unit of life contains two kinds of nucleic acids: Deoxyribonucleic acid (DNA) and the Ribonucleic acid (RNA). While the DNA is the genetic material, the RNA functions in protein synthesis. Both DNA and RNA are polymers built of repeated units known as nucleotides. Each nucleotide contains three parts: a pentose sugar (deoxyribose for DNA and ribose for RNA), a nitrogenous base (a purine and a pyrimidine) and a phosphate group. Both purines and pyrimidines contain nitrogen and carbon in their rings. The purines in DNA and RNA are adenine and guanine while the pyrimidines in DNA are thymine and cytosine and thymine and uracil for RNA. In DNA, the backbone is built of phosphoric acid and deoxribose and the nitrogenous bases are attached to this backbone. The 5' end of the backbone has a free phosphate group on the 5' carbon of the ribose and the 3' end has a free hydroxyl group on the 3'. The DNA is not a single 
polynucleotide chain, rather, it has two complementary chains that are precisely cross-linked by specific hydrogen between purine and pyrimidine bases. The number of adenine is also equal to the number of thymine and the number of cytosine is equal to the number of guanine. Hence, adenine always pairs with thymine(AT) and guanine only pairs with cytosine(GC). The result is now a ladder structure. The ladder is twisted into a double helix with approximately 10 base pairs for each complete turn of the helix. The two DNA strands run in opposite directions(antiparallel), and the 5' end of one strand is opposite the 3' end of the other. The two strands are also complementary i.e. the sequence of bases along one strand specifies the sequence of bases along the other strand [3].

However, for any molecule to serve as the genetic material, it must exhibit 4 features. They are; replication, storage of information, expression of information and variation by mutation. The DNA shows these features. Hence, it is the genetic material.

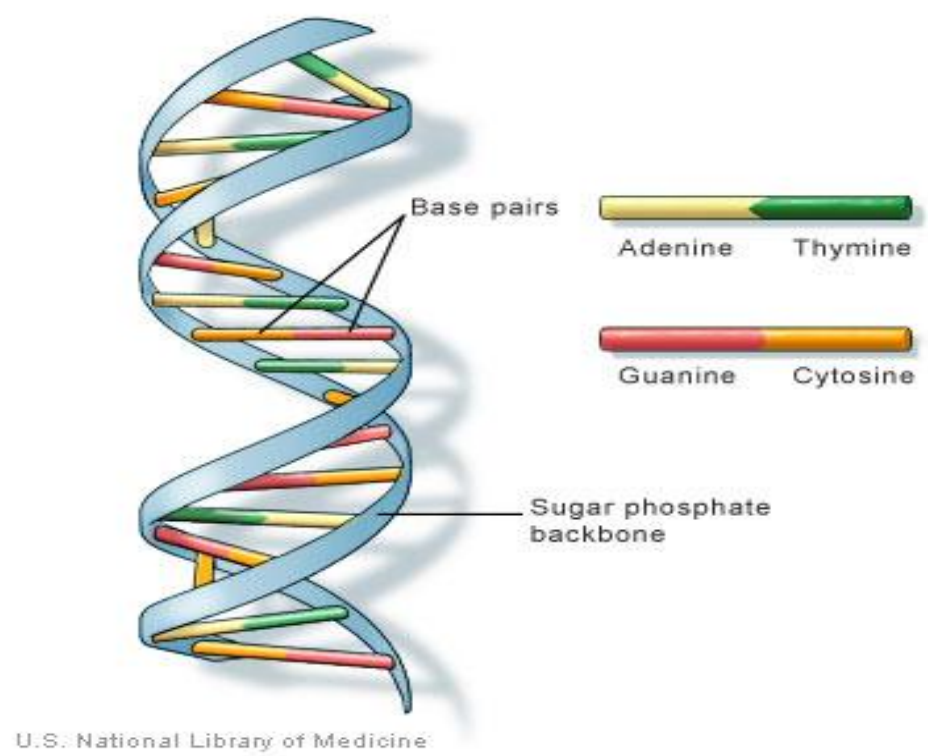

Fig. 1: The structure of DNA .SOURCE: [4].

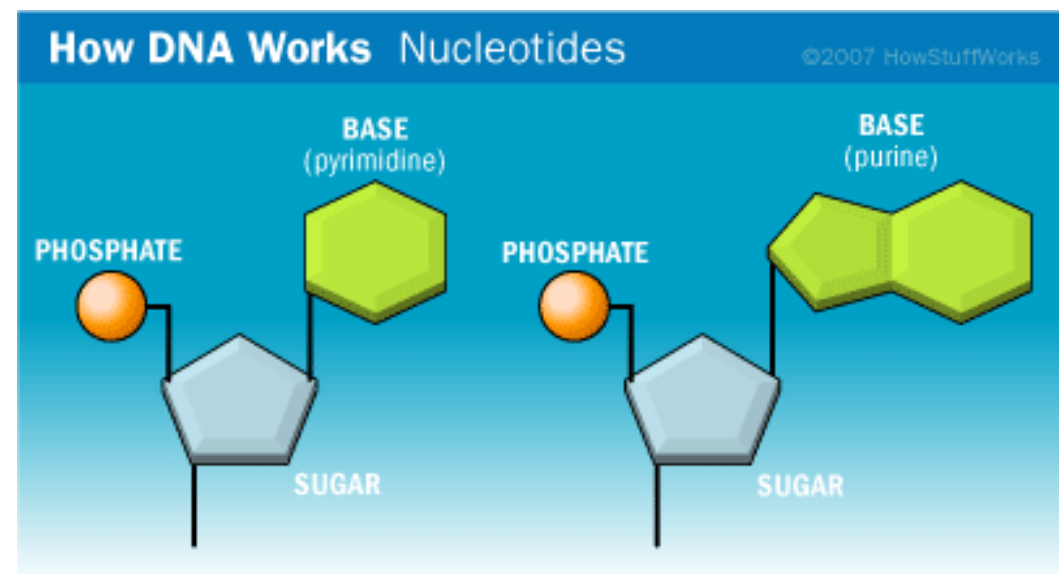

Fig. 2: How DNA works (Nucleotide). Source: [5]

\subsection{Tools And Methods For Genetic Engineering}

There are 3 methods of genetic engineering, they are; gene insertion, gene deletion and gene regulation.

\subsubsection{Gene Insertion}

This is the process of introducing a new gene into an organism. These genes could either be natural or synthesized.

\section{Steps In Gene Insertion}

1. Obtaining the Gene (Gene Isolation): this is easier with the use of restriction enzymes because, it helps isolate specific DNA segments. This enzyme was discovered by Salvador Laura. This enzyme could resist 
destruction by bacteriophages. This DNA cleaving enzyme was isolated from Escherichia coli and called endonuclease. This enzyme cuts viral DNA but not the host DNA because, it first modifies the bacterial DNA by adding a methyl groups to it. By a mechanism yet unknown, a restriction enzyme scans a DNA molecule and stops when it recognises a sequence of four or six nucleotides. The place where the DNA is scissored is called the recognition site. Each segment will have dangling nucleotides called "sticky ends', resulting from restriction enzyme's activity. Because the single stranded ends are complementary, they can pair with each other or with any other DNA fragment that has complementary sticky ends. This makes restriction enzymes the invaluable tools of genetic engineering. The sources of the DNA are immaterial so long as the sticky ends of the DNA fragments are complementary. DNA Ligases are then used to form a permanent link between the ends of the DNA molecules.

2. Selecting The Vector: vectors are the biological vehicles used to transport DNA into host cells. The following are the expected features of a vector:

(a) Must be capable of passing through the cell wall of the host. To do this, it must be small in size, i.e. less than 10 kilo bases $(10 \mathrm{~kb})$.

(b) Must be capable of self replication. To do this the vector should have an origin of replication.

(c) The vector should have just one site where the restriction enzyme will function. Otherwise, the enzyme will scissor the vector at multiple sites.

(d) The vector should have an identifying marker gene for locating it in cells e.g. Antibiotic resistance.

(e) Adaptability of vector to host cell: The gene-altered vector should not place physiological burden on host cells and causing them to die off in culture. Some examples of vectors are: Plasmids, Bacteri phages e.g. T2 Phage and Lambda Phage and viruse e.g. Retroviruses.

3. Production of Recombinant DNA: A restriction enzyme scans the vector e.g. plasmid's double helix unit and recognizes a particular sequence of bases. It opens the plasmid in a staggered fashion, leaving four bases hanging from each cut strand. The four base link up loosely with the complementary bases on the open isolated DNA molecule. Next, the enzyme DNA ligase joins the sugar-phosphate backbones of the plasmid and isolated DNA.

4. Selection of Host Cell: the host is the organism to be transformed. They range from microorganisms to mammals. Microorganisms are transformed so that they can be able to be used in the industries to produce metabolites. Some hosts are; E. coli, Bacillus subtilis, Saccharomyces cerevisiae(yeast) and mammalian cells [6].

\section{DNA Insertion Methods}

(a) Microinjection: this is one widely used DNA procedure for DNA insertion. A microscopic syringe is used to penetrate the cell wall and plasma membrane of the plant cell and propel DNA fragments into the nucleus. Only one cell at a time can be injected and 10,000 or more injections may be required before a successful DNA incorporation to the cell's nucleus is made.

(b) Biological Biolistic (Biolistic): this was developed by Cornell university. Biolistic consists of a cylinder with a catrige containing a nylon projectile. The projectile carries millions of microscopic tungsten spheres, each sphere coated with DNA. When the catridge is fired at a colony of cells, the projectile shoots down the cylinder and a steel placed at the end of the cylinder stops all but the gene carrying spheres. The high velocity and tiny size of spheres speed their entry into the cytoplasm of the cells. This method is costly and the cellular damage is high.

(C). Transfection: this is done by infecting the host cell with the recombinant DNA.

(d). Vortex mixing is another technique that has been developed [7]. 


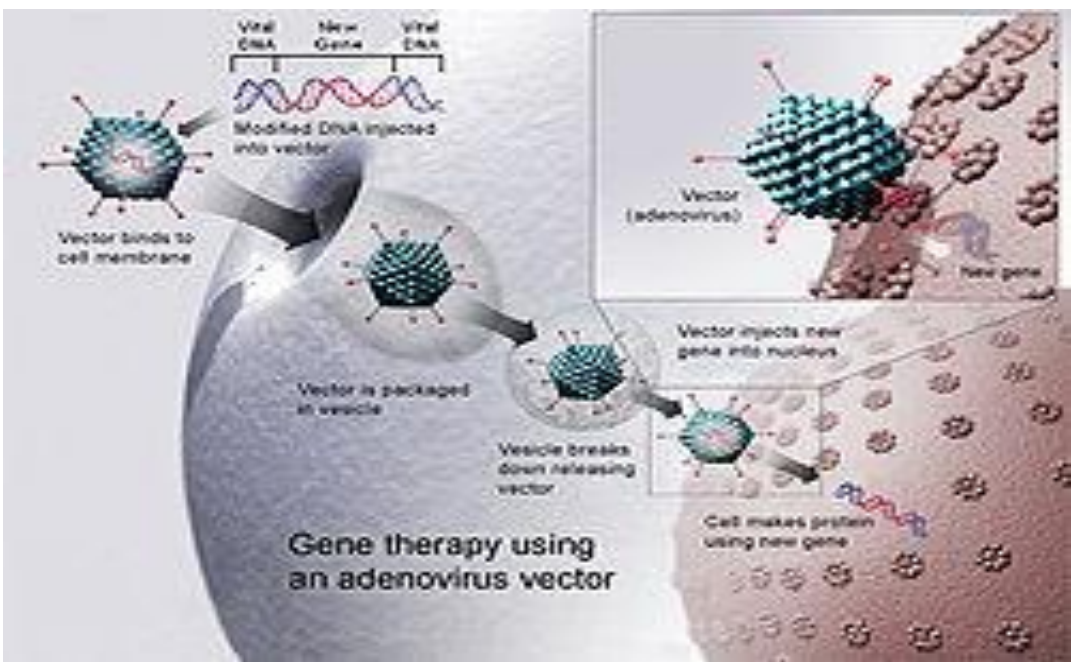

Fig. 3: Gene therapy using an Adenovirus vector. Source: Wikipedia (2009).

\subsubsection{Gene Deletion}

This is the removal of an unwanted and undesired gene from an organism. Here, the restriction enzyme e.g. endonuclease, is used to cut off the undesired gene. The sticky ends of the newly modified gene are allowed to overlap with the vector and the new recombinant DNA is delivered to the host cell.

\subsubsection{Gene Regulation/Termination}

This is used when we don't want to delete the gene. Here, an antisense messenger RNA (mRNA) of the gene is synthesized and introduced into the cell, during protein synthesis, a sense mRNA is produced by the cell and this combines with the antisense mRNA and protein synthesis is inhibited. Antisense molecule is a molecule which binds specifically to a (sense) strand of RNA or to a DNA helix and stops it being used to code for a protein. Antisense molecules are usually chemical derivatives of DNA or RNA.

\subsection{Cases Where Genetic Engineering Has Been Applied Successfully}

The first biotechnology product approved for human health care was the synthetic human insulin which came onto the market in the United States in 1982. Since then, more than 170 biotechnology related drugs and vaccines have been approved by the United States Food and Drug Administration, of which 113 are currently on the market. Another 350 biotechnology medicines, together targeting over 200 diseases, are in the later stages of development. Amongst those approved during 2000 are medicines to treat pneumococcal diseases in children, diabetes, cancer and haemophilia [2]. Genetic engineering has also been used in gene therapy. Gene therapy involves the genetic engineering of a patient's genetic code to remove or replace a mutant gene that is causing disease. There are two broad types of gene therapy that are possible. Germ line, or stem-cell, gene therapy involves altering patients' DNA in their stem (reproductive) cells. The modification to their genetic "blueprint" is permanent, and hereditary. This type of gene therapy is complex, and is considered too risky to undertake until the underlying biology is better understood. It also raises many ethical concerns, for example, over the potential misuse of the therapy to create "designer" babies. At the moment, germ-line gene therapy is banned in many countries. The second type of therapy is somatic gene therapy. This involves engineering cells on a "localized" basis, without affecting the patient's basic genetic "blueprint". The first such therapy was approved in 1990 to treat a four-year-old child suffering from severe combined immune deficiency (SCID). Some of the child's white blood cells were extracted, genetically engineered in the laboratory and infused back into her bloodstream. This successfully strengthened her immune system. Gene therapy techniques for cystic fibrosis have also been approved, and candidate techniques for the treatment of Parkinson's disease, Alzheimer's disease and some cancers are under development. Somatic gene therapy is likely to become very important for the treatment of diseases caused by single mutant genes [2].

\subsection{The Class Aves}

\section{The Science Of Birsds}

These are the birds. They are characterised by the unmistakable presence of feathers. They are said to have evolved from reptiles. The first bird; Archeopteryx was said to have been found about 150million years ago where it drowned and settled to the bottom of tropical freshwater lake in what is now Bavaria [3].

\subsection{Classification Of Birds Based On Development}

Based on habitat, birds can be classified into:

(a) Ratitae: the flightless birds e.g. Turkeys, Ostrich etc. 


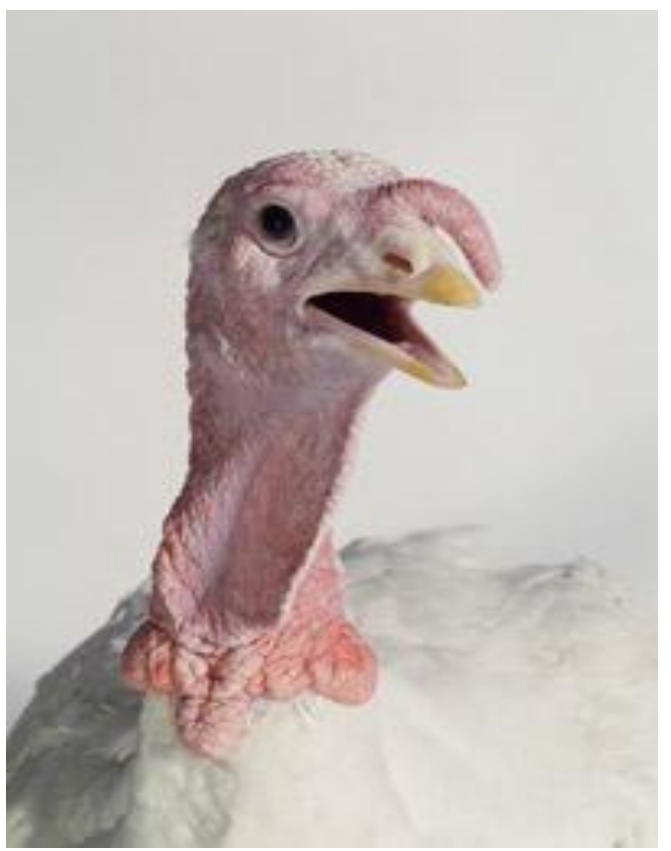

Fig. 4. A broad breasted wild Turkey. Source: [4]

(b) Carinate: The flying birds.

However, based on development, birds are classified into 4, namely; precocious, semi precocious altricial and semi altricial.

Precocial And Altricial Young: Two words describing the degree of development in young birds at hatching are precocious and altricial. A precocial bird is capable of moving around on its own soon after hatching. Altricial means incapable of moving around on its own soon after hatchling. Nidicolous is used to describe young that remain in the nest. All nidifugous birds are precocial, but some nidicolous birds are precocial and they remain in the nest even though capable of locomotion [8].

Instead of a sharp dividing line between hatchlings that are precocial and those that are altricial, there is a gradient of precociality. In this guide, we recognize the following categories of young:

Precocial youngs are hatched with eyes open, covered with down, and leave the nest within two days. There are four levels of precociality, although only three are found in North American birds. Level 1 of development (precocial 1) is the pattern found in the chicks of megapodes (Australian Malee fowl, Brush Turkeys, etc.), which are totally independent of their parents. The megapode young are incubated in huge piles of decaying vegetation, and upon hatching dig their way out, already well feathered and able to fly. No North American birds show this extreme precociality. Precocial 2 development is found in ducklings and the chicks of shorebirds, which follow their parents but find development is found in ducklings and the chicks of shorebirds, which follow their parents but find their own food. The young of game birds, however, trail after their parents and are shown food; they are classified as precocial 3. Precocial 4 development is represented by the young of birds such as rails and grebes, which follow their parents and are not just shown food but are actually fed by them.

Semi-precocial birds are hatched with eyes open, covered with down, and capable of leaving the nest soon after hatching (they can walk and often swim), but stay at the nest and are fed by parents. Basically precocial but nidicolus, this developmental pattern is found in the young of gulls and terns.

Semi-altricial birds are covered with down, incapable of departing from the nest, and fed by the parents. In species classified as semi-altricial 1, such as hawks and herons, chicks hatch with their eyes open. Owls, in the category semi-altricial 2 , hatch with the eyes closed. If all young were divided into only two categories, altricial and precocial, these all would be considered altricial

Altricial birds are hatched with eyes closed, with little or no down, incapable of departing from the nest, and fed by the parents. All passerines are altricial. 


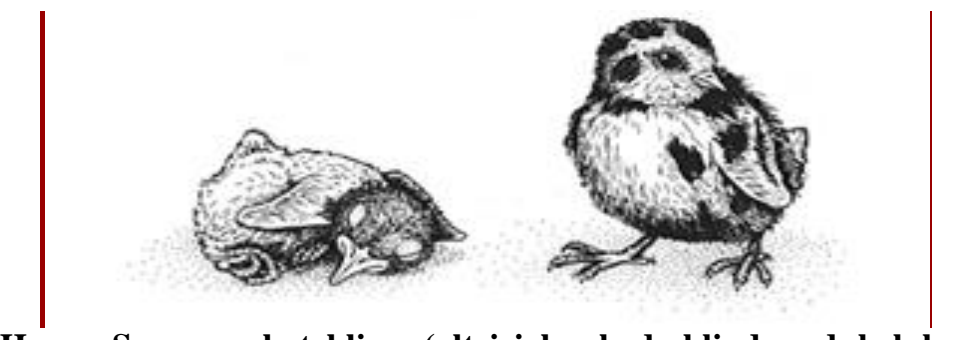

Fig.5. Left: House Sparrow hatchling (altricial-naked, blind and helpless on hatching). Right: Ruffed Grouse hatchling (precocial 3-downy, open-eyed, mobile on hatching, follows parents and is shown food). Source: [4].

Table 1: Characteristics Of Nestlings (modified from O'Connor, 1984)

\begin{tabular}{|c|c|c|c|c|c|c|}
\hline $\begin{array}{l}\text { TYPE } \\
\text { DEVELOPMENT }\end{array}$ & \begin{tabular}{l|l} 
OF & $\begin{array}{l}\text { DOWN } \\
\text { PRESENT? }\end{array}$
\end{tabular} & $\begin{array}{l}\text { EYES } \\
\text { OPEN? }\end{array}$ & MOBILE?. & $\begin{array}{l}\text { FEED. } \\
\text { SELVES? }\end{array}$ & $\begin{array}{l}\text { PARENTS } \\
\text { ABSENT? }\end{array}$ & EXAMPLES \\
\hline Precocial 1 & Yes & Yes & Yes & Yes & Yes & Megapodes \\
\hline Precocial 2 & Yes & Yes & Yes & Yes* & No & Ducks, Plovers \\
\hline Precocial 3 & Yes & Yes & Yes & Yes (t) & No & Quail, Turkey, Fowl \\
\hline Precocial 4 & Yes & Yes & Yes & Yes/No & No & Grebes, Rails \\
\hline Semi-precocial & Yes & Yes & Yes/No & No & No & Gulls, Terns \\
\hline Semi-altricial 1 & Yes & Yes & No & No & No & Herons, Hawks \\
\hline Semi-altricial 2 & Yes & No & No & No & No & Owls \\
\hline Altricial & No & No & No & No & No & Passerines \\
\hline
\end{tabular}

$\mathrm{t}=$ Precocial 3 are shown food.

.....* Precocial 2 follow parents but find own food.

These different modes of development have evolved because, they are tied into two important aspects of the bird's environment namely: food availability and predation pressure. Precociality puts a premium on the ability of females to obtain abundant resources before laying. They must produce energy-rich eggs to support the greater in-egg development of the chicks (eggs of precocial birds may contain almost twice the calories per unit weight as those of altricial birds). Females of altricial species do not have such large nutritional demands before egg laying, but must be able (with their mates) to find sufficient food to rush their helpless young through to fledging. While the young are in the nest, the entire brood is extremely vulnerable to predation and is dependent on concealment of the nest and parental defence for survival. In contrast, precocial young, having left the nest, have some ability to avoid predation, and there is a much smaller chance of the entire brood (as opposed to single chicks) being devoured. Interestingly, there seems to be an evolutionary trade-off in bird brain sizes related to the degree of precocity.

Precocial species have relatively large brains at hatching-as one might expect since the young, to one degree or another, must be able to fend for themselves. But precocial species trade for this advantage an adult brain that is small in relation to their body size. Altricial young, in contrast, are born small-brained, but on the pro-tern-rich diet provided by the adults (and with their highly efficient digestive tracts) postnatal brain growth is great, and the adults have proportionally larger brains than precocial species.

Parrots have evolved their way into the best of both worlds. They are altricial, but the female invests in a nutrient-rich egg just like females of precocial species. Parrots are among the most intelligent of birds.

\subsection{Features Of Birds}

The most obvious adaptation to flight is the wing, but because flight is so energetically demanding birds have evolved several other adaptations to improve efficiency when flying. Birds' bodies are streamlined to help overcome air-resistance [5]. Birds have spindle shaped body, with 4 divisions; head, neck, trunk and tail, limbs are paired, with fore limb adapted for flying and hind limb for perching, walking and swimming, foot is chiefly with four toes, sweat glands are absent, oil or preen glands is at root of tail, pinna of ear is rudimentary, skeleton is fully ossified with air cavities or sacs, they've small ribs and fused vertebrae, they lack teeth, except for the young of Hoatzin, well developed nervous system with brain and 12 pairs of cranial nerves, circulatory system made up of 4 chambered heart with the right aortic arc persisting, they possess nucleated red blood cells and have reduced renal portal system, they are endothermic, respiration is by slightly expansible lungs, with air sacs among the visceral organs and skeleton, excretion is by metanephric kidney, ureters open into cloaca, there 
is no bladder, semi solid urine and uric acid is the main nitrogenous waste, sexes are separate, testes are paired with vas deferens opening into the cloaca, females have only left ovary and left oviduct, copulatory organ is lacking but present in ducks, geese and others, fertilization is internal, amniotic eggs with much yolk and hard calcerous shells, incubation is external, young can be active on hatching, or helpless and naked (altricial).

\subsection{The General Process For Genetic Modification Of Farm Animals}

\section{The Making Of Transgenic Birds}

STEP 1: Isolate the DNA desired molecule

STEP 2: Extract fertilized egg from the bird

STEP 3: Inject the extracted DNA molecule into the nucleus of the fertilized egg with a micro injector

STEP 4: The DNA integrates with the nucleus of the cell.

STEP 5: The eggs are transferred to a foster mother.

STEP 6: In due time, after the gestation period, the young/eggs are laid.

STEP 7: After hatching, a blood sample is taken from the bird and tested for presence of inserted DNA.

\subsection{Limitations to the Ideal Process for Genetic Modification}

One of the obstacles in the production of transgenic aves was the low-efficiency of introducing foreign DNA into the chicken genome. Procedures that have worked for other animals are difficult, if not impossible, due in part to the unique reproductive physiology of the chicken [9].

Researchers using birds in genetic engineering experiments are trying to overcome the inaccessibility of the birds' fertilized ova. In mammals, such as mice, the fertilized ova are relatively easy to obtain in large numbers, and they have visible pronuclei for DNA microinjection. However, a hen produces only one fertilized ovum per day. This ovum, the yolk, is large and fragile. Its cytoplasm makes the pronucleus impossible to visualize for DNA microinjection. By the time the egg is laid the embryo has already begun to develop on the yolk and has about 60,000 cells. Another problem is that the viruses that are used to carry the foreign genes into the birds can dangerously replicate: "The major problem associated with the use of retroviral vectors is the generation of infectious virus that can be indefinitely transmitted".

Also, because of the unique features of avian reproduction. During fertilization in birds, several sperms can penetrate the ovum instead of one sperm. So, it is impossible to identify the male pronucleus that will fuse with the female pronucleus.

\subsection{THE PRACTICAL PROCESSES USED FOR GENETIC MODIFICATION OF BIRDS}

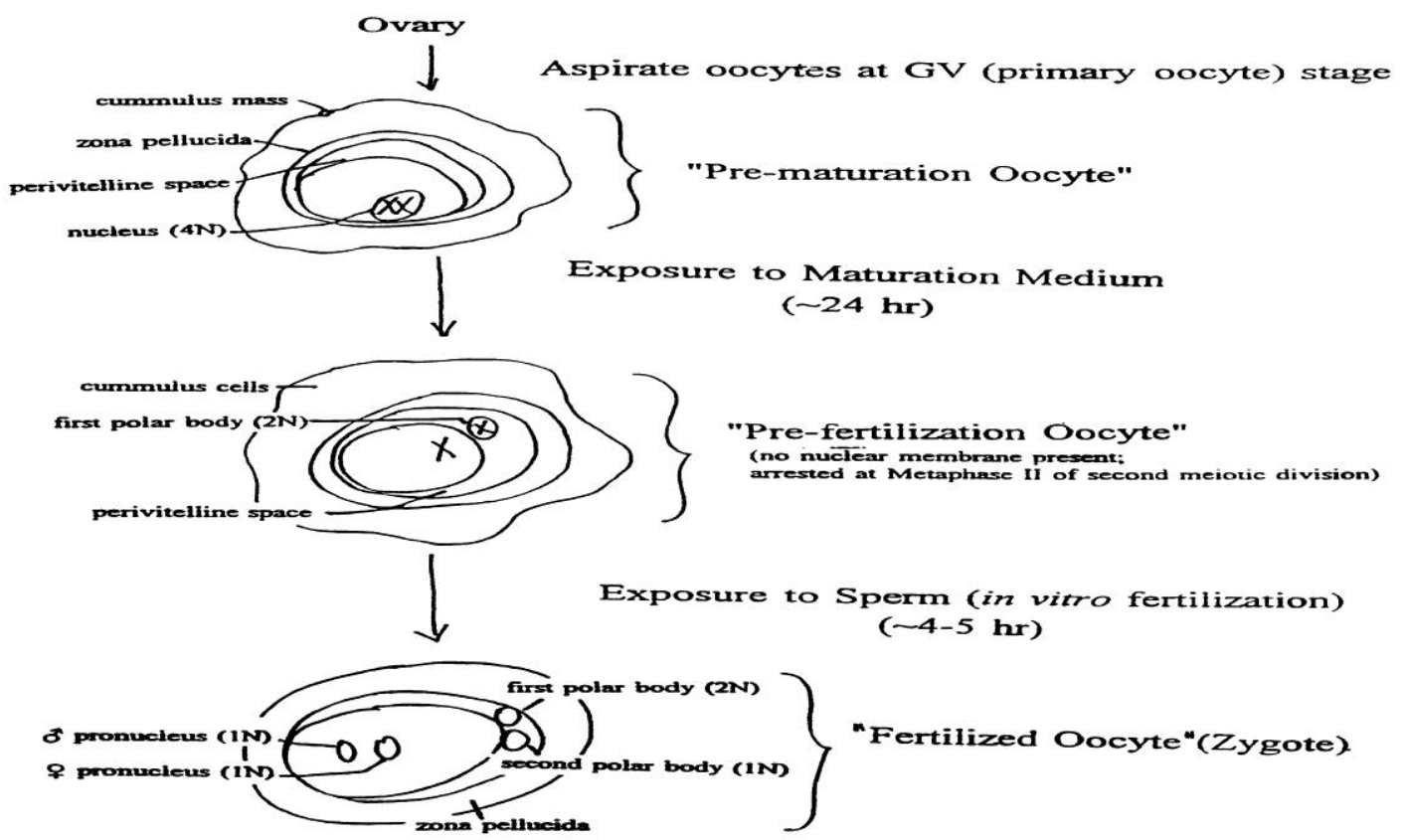

FIG. 6: The Practical Processes Used For Genetic Modification Of Birds

Source: [4].

In the mid-1980s, a researcher at the Institute of Animal Physiology and Genetics Research in Edinburgh injected foreign DNA into single-cell chicken embryos and then cultured them through hatching in vitro. The embryos was removed from the hen's oviduct, placed in various vessels containing solutions similar to those in an egg, then placed in artificial eggshells sealed with glue made from albumen and antibiotics, and 
mechanically incubated through hatching. New Scientist called them "the world's first test-tube chickens" allowing researchers to create "super-chicken' by inserting foreign DNA into chick embryos" [10].

A National Institutes of Health (NIH)-supported study of the avian liver was described to express (manifest a trait linked to a particular gene) recombinant proteins in vivo. The research was designed to estimate use of the avian liver "to influence growth rates, metabolism, body fat composition, and the effectiveness of several drugs" and be a model for treatment of human genetic diseases. In the experiment, avian leukosis retroviral vectors were used to introduce a recombinant rat neomycin-resistance gene into chicken embryos before and during incubation. Upon hatching, the surviving chicks were killed by cervical dislocation (neckbreaking) and their tissues were frozen in liquid nitrogen for further analysis [11].

A method of producing transgenic chickens based on microinjection of foreign DNA from two different types of bacteria into the birds was described by some researchers [12]. First, the researchers artificially inseminated hens with semen pooled from young roosters. Then they killed the hens by intravenous injection of an anaesthetic overdose of Expiral. Next they opened the dead hens' abdomens and removed the oviduct section containing the shell-less fertile eggs. They then placed the eggs in surrogate shells and injected the bacterial DNA into the cytoplasm of the germinal discs of the zygotes (the one-cell embryos). Next they filled the shells with a culture medium and sealed them shut. Following this, they analyzed the fate of the plasmid DNA microinjected into the germinal discs of embryos who survived for at least 12 days in culture. Of the 128 original ova, seven chicks survived to sexual maturity. Of these, one rooster transmitted the bacterial DNA to 3.4 of his offspring. Of these offspring, those who survived to sexual maturity were bred to produce transgenic offspring, "demonstrating that stable transmission of foreign DNA can be obtained by our method"

The aim of a study published in 1995 in Transgenic Research was "to develop a safe retroviral system to obtain transgenic chickens" [13]. The problem addressed was the fact that replicating avian retroviruses used in vivo can be pathogenic even after a long time, increasing the risk of disease states associated with chronic viral infection. As the avian spleen necrosis virus (SNV) is closely related to mammalian retroviruses, and it has been found that SNV can infect human cells, the researchers sought a way to produce transgenic chickens using replication defective vectors based on a system (an "ecotropic" system) which is able to infect avian cells only. Using vectors derived from ecotropic avian leukosis viruses, the researchers microinjected foreign bacterial genes into the sub germinal cavity of unincubated chicken embryo blastoderms (tiny reproductive cells). DNA was then extracted from these embryos and injected into another group of unincubated chicken embryos who were then incubated. Of the group of 1550 chicken embryos infected with the ecotropic vectors, only 36 hatched. According to the researchers, most died early after injection due mainly to the opening of their eggshells. One surviving rooster managed to transmit vector DNA to his progeny, at a rate of 2.2 percent. The researchers concluded that their data showed "the efficacy of ecotropic avian retroviral vectors to produce transgenic chickens".

\section{Transgenic Birds And Their Uses}

Genetically modified birds are also known as transgenic birds. An organism that has had part of another species' genome transferred into its own through the techniques of genetic engineering is a transgenic organism. It should be noted that a transgenic organism is also called a chimera. Cisgenic birds are those who obtained genes from birds of the same genus but different species. Transgenic birds however, obtain their genes from animals or organisms of other species. The points to be listed below are the areas where transgenic birds have been successfully made. Chickens (Gallus gallus) are suitable for gene manipulation because, unlike other domestic animals, they mature quickly, and a single bird can have thousands of offspring. Also, foreign genes need to be inserted into one generation, which passes the genes on [10].

\subsection{Transgenic Birds for Improved Egg Production}

A major venture in this area is the mass production of egg yolks with antibodies to be used as artificial growth promoters in chickens and other farmed animals since the use of growth-promoting antibiotics is being reduced or eliminated in meat-animal production as a result of having contributed to the worldwide growth of antibioticresistant bacteria [14]. Hens and their eggs are being genetically engineered to be protein and antibody "factories." They are being used for the following other uses:

- $\quad$ To make vaccines.

- To produce antibodies in eggs that are added to pig feeds to fight off bacterial infections such as E.

coli.

- $\quad$ To produce growth-promoting antibodies in egg yolks to be fed to farmed animals to increase their growth rates by disrupting their normal peptide and gut processes, thus, for example, tricking animals who are already full to continue eating.

- $\quad$ To produce recombinant lactoferrin and lysozyme as alternatives or supplements to growth-promoting antibiotics and/or antibodies in poultry diets. 
- To produce antibodies to fight cancer in humans.

- To secrete human growth hormone to help dwarfs grow taller.

- To produce eggs with lower cholesterol for human consumption.

- To produce soy isoflavons in eggs sold for human consumption. For example, poultry researchers at the University of Maryland and the University of Arkansas are experimenting with Japanese quails to see if soy isoflavons can be transferred and accumulated in their eggs.

- $\quad$ To produce yolk antibodies, specifically, avian immunoglobulin, or IgY, for a range of diagnostic systems as a substitute for the use of laboratory mammals.

- As fertile "egg-type" hens' eggs carrying "meat-type" chicken cells in order to mass-produce cloned "meat" (broiler) chickens, and thus do away with the expensive maintenance of broiler breeder flocks. In this program, "certain individuals from the pedigree flocks would be cloned and the genetic material placed into fertile eggs. Cloning companies would culture cells and then place them into the embryo of a fertilized recipient egg forming a chick called a chimera. The recipient fertile eggs could come from flocks like leghorns that produce a large number of inexpensive eggs. When those eggs are hatched, they are broilers" [15].

In a typical condition, eggs also produce a large amount of ovalbumin in their reproductive tract that becomes part of the egg. Transgenic eggs are engineered to secrete other types of protein into the egg so that they can be easily isolated.

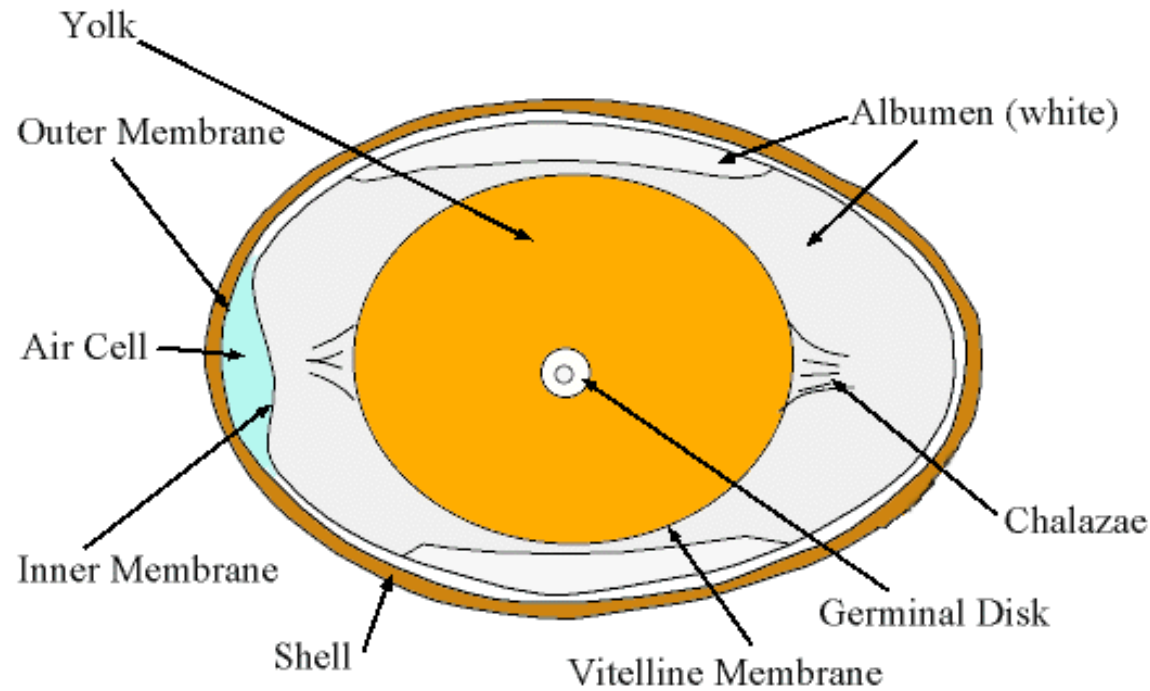

Fig.7. An Avian egg and its parts. Source: [5].

\subsection{Transgenic Birds for Improved Meat Production}

The whole idea of transgenic birds for meat production is to get the time from chick to market weight down from 42 days to a brief time which is technically feasible e.g. 30days. The days needed to raise a 35 pound tom (male turkeys) today is 38 percent less than it took in 1966. However, today's hens require about 33 percent fewer days to reach a 16-pound market weight [16]. The yearly average body weight of 18-week-old toms has continued to rise from 1966 up to 2001. Following this trend to the year 2010, commercial toms should easily achieve a live weight of over 35 pounds by 18 weeks of age. Meanwhile, geneticists were searching for a fat-reducing gene to insert into broiler chickens because selection for fast rapid growth has increased the number of fat cells in these birds [17]. With these and other projects in mind, genetic engineers were eager to manipulate the chicken's DNA to make the birds grow larger, leaner, and faster, and to change the shape and composition of their bodies to fit the "value-added," deboned chicken parts market overtaking the traditional sale of whole birds. 


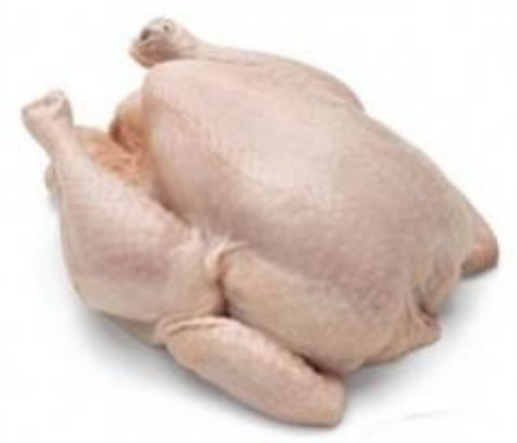

Fig.8.A Modified Turkey. Source: [5].

\subsection{Transgenic Birds For Improved Egg And Meat Production}

Biotech Companies are presently seeking to Bridge the Gap Between Egg Laying and Meat Production in Chickens. Traditional breeding techniques are starting to hit some limits. For instance, when breeders select birds that grow fatter faster, these birds tend to be duds at laying eggs. But what if there was a way to have the best of both worlds, to create a breed that reached market weight in record time, but also had a high egg-laying potential, so breeders could quickly supply farmers with billions of these new super-birds.

India has developed a transgenic chicken variety that is fleshier than normal breeds, and can reportedly also be used in the treatment of diseases. This breakthrough research could help boost production in a country where the annual domestic consumption of poultry and poultry products is worth more than 300 billion rupees (US\$6.8 billion.)The tool used to genetically modify the chicken was developed by a team of 3 scientists at the Hyderabad-based Project Directorate on Poultry after 2 years of research using a gene of jellyfish and spermatozoa of a specific variety of chicken from the institute. Bhattacharya, T.K., the head scientist said it is ready for commercial use. These chickens can enhance productivity and give a huge quantity of flesh. Also, the transgenic birds can produce up to 300 eggs over 72 weeks, which is more than twice the number of eggs produced by normal varieties of chickens. The institute hatched 263 chicks in its study group, of which 16 were found to be transgenic. The efficiency of the institute's method of producing transgenic varieties is about 6 percent.

\subsection{Transgenic Birds For Erythropoietin Production}

Accordingly, it is an object of the present invention to provide a transgenic bird producing erythropoietin at high concentration levels as well as a method for constructing the same. The present inventors made intensive investigations and, as a result, found that a transgenic bird producing erythropoietin at high concentration levels can be obtained by the method which comprises incubating a fertilized avian egg, infecting the early embryo formed after egg laying, except for the blastoderm stage immediately following egg laying, with a replication-deficient retroviral vector containing a foreign erythropoietin gene and allowing the embryo to hatch. Such finding has now led to completion of the present invention. The bird to be used in the practice of the invention is not particularly restricted but includes those domestic fowls and pet birds which are reared for meat and egg production, for example chickens, turkeys, ducks, ostriches and quails. Among them, chickens and quails are preferred since they are readily available and are prolific layers.

The foreign erythropoietin gene to be used in the practice of the invention is not particularly restricted but preferably is a mammal-derived one, more specifically a human-derived one or one derived from a pet animal such as a dog, for instance. For expression thereof in avian cells, the foreign erythropoietin gene to be used in the practice of the invention is preferably connected to an appropriate promoter on the downstream side thereof.

\subsection{Transgenic Birds For Bird Flu Resistance}

The long-term threat of an avian flu pandemic could be greatly reduced by a project to produce genetically modified chickens that can resist lethal strains of the virus. British scientists are genetically engineering chickens to protect them against the H5N1 virus that has devastated poultry farms in the Far East, with a view to replacing stocks with birds that are not susceptible to influenza. The technique should also offer protection against many other strains of flu with the potential to start a human pandemic, such as the H7 subgroup that was responsible for an outbreak in Dutch poultry in 2003. If chicken populations were to be replaced with transgenic birds that were resistant to flu, it would remove a reservoir of the virus and make it much harder for it to spread to humans and trigger a pandemic. The team, led by Laurence Tiley, Professor of Molecular Virology at Cambridge University, and Helen Sang, of the Roslin Institute, near Edinburgh, has already shown that chicken cells can be protected against flu by inserting small pieces of genetic material. The 
researchers are now ready to begin a similar procedure with eggs and the first experiments are expected within weeks. Any breakthrough, however, will come too late to have an impact on the present outbreak of H5N1. Even if the technique works, it will be several years before it can be used to stock farms and it also faces important regulatory hurdles and a battle to win over public opinion. If these obstacles are overcome and farmers are willing to adopt GM chickens, the entire world stock could be replaced fairly quickly. "Once we have regulatory approval, we believe it will only take between four and five years to breed enough chickens to replace the entire world population," Professor Tiley said. "Developing flu-resistant chickens has clear benefits for human health and animal welfare, as we wouldn't have to slaughter chickens around the world. Chickens provide a link between the wild bird population, where avian influenza thrives, and humans, where new pandemic strains can emerge. Removing that bridge will dramatically reduce the risk posed by avian viruses." The research team is following three parallel approaches. One involves inserting a working copy of a gene that makes an antiviral protein called Mx, which is defective in many chicken breeds, and should improve their ability to fight off $\mathrm{H} 5 \mathrm{~N} 1$ and other strains. The second approach is to harness a technique called RNA interference, in which small fragments of the genetic signalling chemical RNA are used to disrupt the workings of the flu virus. By engineering chicken cells to make small RNA molecules that confuse the flu virus, the scientists hope to confer resistance to a wide variety of strains. The third strategy is similar to the second, but involves using RNA molecules as decoys, which trick the flu virus into copying them rather than itself. All three could potentially be incorporated in the same GM chickens.

\subsection{Other Possibilities In Genetic Engineering Of Birds}

\section{Issues In Biotechnology}

The making of a Libird: it is still a fiction to make a Libird. Below is a plan of how the bird will look like. The purpose has not been discussed, but we can conclude that the teeth will at least help the bird to tear flesh.

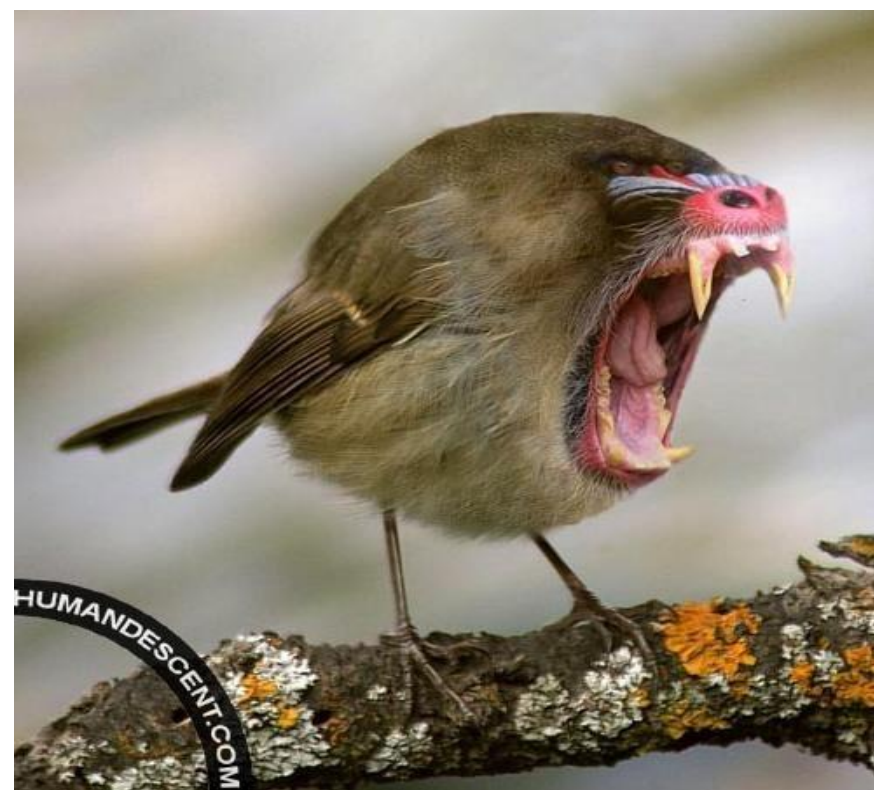

Fig.9. The Plan of a bird to be modified. Source: Wikipedia.

Secondly, it is possible to modify a precocious bird to an altricial bird. As explained above, it seems that precocious young has all the advantage, with their greater ability to find food and to escape predation. However, altricial birds have the advantage of laying relatively small eggs with minimal yolk supplies. This makes the mother invest a little in her eggs and can easily replace eggs lost to predation or extreme weather condition. Furthermore, altricial young also grow faster due to the growth potential of immature tissue [3].

\subsection{Issues In Biotechnology}

So many concerns have been raised about genetic engineering and biotechnology. people are afraid and still not convinced to eat and them. There are a lot of ethical, environmental, health and safety issues in biotechnology. also, people are concerned with loss of natural species and biodiversity. Below are the issues that have been raised in biotechnology. 
(1). Environmental hazards:

Unintended harm is done to other organisms: Last year a laboratory study was published in Nature showing that pollen from biotechnology (B.t.) corn caused high mortality rates in monarch butterfly caterpillars. Monarch caterpillars consume milkweed plants, not corn, but the fear is that if pollen from B.t. corn is blown by the wind onto milkweed plants in neighbouring fields, the caterpillars could eat the pollen and perish. Although the Nature study was not conducted under natural field conditions, the results seemed to support this viewpoint. Unfortunately, B.t. toxins kill many species of insect larvae indiscriminately; it is not possible to design a B.t. toxin that would only kill crop-damaging pests and remain harmless to all other insects. This study is being reexamined by the U.S Department on Agriculture (USDA), the U.S. Environmental Protection Agency (EPA) and other non-government research groups, and preliminary data from new studies suggests that the original study may have been flawed. This topic is the subject of acrimonious debate, and both sides of the argument are defending their data vigorously. Currently, there is no agreement about the results of these studies, and the potential risk of harm to non-target organisms will need to be evaluated further.

Reduced effectiveness of pesticides: Just as some populations of mosquitoes developed resistance to the nowbanned pesticide DDT, many people are concerned that insects will become resistant to B.t. or other crops that have been genetically-modified to produce their own pesticides.

Gene transfer to non-target species Another concern is that crop plants engineered for herbicide tolerance and weeds will cross-breed, resulting in the transfer of the herbicide resistance genes from the crops into the weeds. These "superweeds" would then be herbicide tolerant as well. Other introduced genes may cross over into nonmodified crops planted next to GM crops.

There are several possible solutions to the three problems mentioned above. Genes are exchanged between plants via pollen. Two ways to ensure that non-target species will not receive introduced genes from GM plants are to create GM plants that are male sterile (do not produce pollen) or to modify the GM plant so that the pollen does not contain the introduced gene. Cross-pollination would not occur, and if harmless insects such as monarch caterpillars were to eat pollen from GM plants, the caterpillars would survive.

Another possible solution is to create buffer zones around fields of GM crops. For example, non-GM corn would be planted to surround a field of B.t. GM corn, and the non-GM corn would not be harvested. Beneficial or harmless insects would have a refuge in the non-GM corn, and insect pests could be allowed to destroy the non-GM corn and would not develop resistance to B.t. pesticides. Gene transfer to weeds and other crops would not occur because the wind-blown pollen would not travel beyond the buffer zone .Estimates of the necessary width of buffer zones range from 6 meters to 30 meters or more. This planting method may not be feasible if too much acreage is required for the buffer zones.

\section{(2). Human health risks}

Allergenicity: Many children in the U.S and Europe have developed life-threatening allergies to peanuts and other foods. There is a possibility that introducing a gene into a plant may create a new allergen or cause an allergic reaction in susceptible individuals. A proposal to incorporate a gene from Brazil nuts into soybeans was abandoned because of the fear of causing unexpected allergic reaction.

Unknown effects on human health There is a growing concern that introducing foreign genes into food plants may have an unexpected and negative impact on human health. A recent article published in Lancet examined the effects of GM potatoes on the digestive tract in rat. This study claimed that there were appreciable differences in the intestines of rats fed GM potatoes and rats fed unmodified potatoes. Yet critics say that this paper, like the monarch butterfly data, is flawed and does not hold up to scientific scrutiny. Moreover, the gene introduced into the potatoes was a snowdrop flower lectin, a substance known to be toxic to mammals. The scientists who created this variety of potato chose to use the lectin gene simply to test the methodology, and these potatoes were never intended for human or animal consumption.

On the whole, with the exception of possible allergenicity, scientists believe that GM foods do not present a risk to human health.

\section{(3). Economic concerns}

Bringing a GM food to market is a lengthy and costly process, and of course agri-biotech companies wish to ensure a profitable return on their investment. Many new plant genetic engineering technologies and GM plants have been patented, and patent infringement is a big concern of agribusiness. Yet consumer advocates are worried that patenting these new plant varieties will raise the price of seeds so high that small farmers and third world countries will not be able to afford seeds for GM crops, thus widening the gap between the wealthy and the poor. It is hoped that in a humanitarian gesture, more companies and non-profits will follow the lead of the Rockefeller Foundation and offer their products at reduced cost to impoverished nations. 
Patent enforcement may also be difficult, as the contention of the farmers that they involuntarily grew Monsanto-engineered strains when their crops were cross-pollinated shows. One way to combat possible patent infringement is to introduce a "suicide gene" into GM plants. These plants would be viable for only one growing season and would produce sterile seeds that do not germinate. Farmers would need to buy a fresh supply of seeds each year. However, this would be financially disastrous for farmers in third world countries who cannot afford to buy seed each year and traditionally set aside a portion of their harvest to plant in the next growing season. In an open letter to the public, Monsanto has pledged to abandon all research using this suicide gene technology [18].

\subsection{Misery Of Modern Meat Birds}

Genetically manipulating a bird, that would normally weigh little more than a pound at six weeks old into a bird weighing four and a half or five pounds at this age (growing at a rate of three and a half times faster than normal), has created major metabolic and skeletal disorders in meat-type chickens. Their mortality rate is seven times that of laying hens of the same age, and two percent of these birds die of heart failure in their infancy. At least a quarter of all broiler chickens are lame, and studies show that they are in pain. When given a choice between food with painkillers and regular food, the birds quickly identify the food with the painkillers and eat only that $[19]$.

Given the multitude of problems caused by forced rapid growth using 20th-century selective breeding methods, the poultry industry is considering cloning and other genetic modification procedures to multiply chickens for the world market in years to come [20].

\subsection{A Consensus}

Biotechnology should not be wiped completely; instead, there should be regulations and careful screening of things done with biotechnology.

\subsection{Biotechnology Regulations}

The National Institute of Health was the first federal agency to assume regulatory responsibility in the United States. The Recombinant DNA Advisory Committee of the NIH published guidelines for working with recombinant DNA and recombinant organisms in the laboratory. Nowadays, the agencies that are responsible for the biotechnology regulation are: USDA that regulates plant pests and medical preparation from living organisms, Environmental Protection Agency (EPA) that regulates pesticides and herbicides, and the Food and Drug Administration (FDA) which ensures that the food and drug products are safe and effective.

However, European Food Safety Authority's (EFSA) Genetically Modified Organism (GMO) Panel has established a working group to draft guidance for the food and feed safety assessment of products derived from GM animals. Also, to effectively assess environmental safety, taking into account the diversity of animal habitats, the GMO Panel is setting up three dedicated working groups. These groups will draft specific guidance for GM fish, GM insects, and GM mammals and birds. In order to gather the necessary background information for this environmental risk assessment, EFSA has launched and awarded three separate calls for tenders, with the aim of identifying information available in the public domain and defining the risk assessment criteria for GM fish, GM insects and GM birds and mammals.

Finally, there should be a rule that genetically modified foods should be labelled. This is to make eating it a thing of choice i.e. whether or whether not to eat such foods based on ones beliefs and practices.

\section{Conclusion}

God has endowed us with so many potentials. The question still remains: are we to exploit all? Or are we to leave some things buried seeing the enormous effects they have on everything else on earth.

\section{Acknowledgement}

I want to appreciate my husband, Engr. Patrick Okolo, Prof. F. C. Okafor and my family; the Echefu's.

\section{References}

[1]. W. Bains, Biotechnology from A to Z, Oxford University Press, Oxford (GB), 1993

[2]. United Nations Conference on Trade Development, Key issues in biotechnology, pages 1, 2002.

[3]. P. Hickman, S. Roberts, L. Keen, A. Larson, H. L’Anson, and J. Eisenhour, Integrated Principles of Zoology, McGraw-Hill, New York, 2008.

[4]. Wikipedia, Biotechnology, Page 1, 2010.

[5]. Wikipedia, Bird flight, Page 1, 2011

[6]. E. Alcamo, DNA Technology, the Awesome Skill, Wm. C. Brown Publishers, USA, 1996

[7]. S. Mader, Biology, Mc GrawHill Companies, 946 Pages, 2011.

[8]. R. Paul, S. David, and D. Wheye, Precocial and altricial young, Stanford University, Page 1, 1998. 
[9]. A. Harvey, Consistent production of transgenic chickens using replication-deficient retroviral vectors and high thorough put screening procedures, Poultry Science, Volume 81, Issue 2, Page 202, 2002.

[10]. L. Milgrom, Test tube chicks pave way for 'super-animals', New Scientist, Page 1, 1998.

[11]. 11. R. Cook, Liver-specific expression of a phosphoenolpyruvate carboxykinase-neo gene in genetically modified chickens, Poultry Science, Volume 72, Page 554, 1993.

[12]. J. Love, Transgenic birds by DNA microinjection, Bio/Technology, Volume 12, Page 60, 1994.

[13]. P. Thoroval, Germ line transmission of exogenous genes in chicken using helper-free ectotropic avian leukosis virus-based vectors, Transgenic Research, Volume 4, Issue 6, Page 369, 1995.

[14]. M. Howie, Modified egg yolk may produce antibodies to livestock, Feedstuffs, Page 1, 1997.

[15]. P. Aho, Feathered Success. WATT Poultry USA, Page 30, 2002.

[16]. P. Ferket, Growing bigger and faster. WATT Poultry USA, Page 40, 2002

[17]. R. Gyles, Designing Foods: Animal Products Options in the Market place, National Academy Press, Washington DC, 1998.

[18]. D. Whitman, Genetically modified foods: harmful or helpful, Pro Quest, Page 1, 2000.

[19]. T. Danbury, Self-selection of the analgesic drug carprofen by lame broiler chickens. Veterinary Method, Volume 146, Page 307, 2000 .

[20]. R. Leach, Poultry industry should reconsider if bigger is better. Feedstuffs, Page 1, 1996. 